\title{
Decontamination of Surfaces Exposed to Carbon-Based Nanotubes and Nanomaterials
}

\author{
Paul Su, ${ }^{1}$ Babak Haghpanah, ${ }^{2}$ William W. Doerr, ${ }^{1}$ Zahra Karimi, ${ }^{2}$ Syed Hassan, ${ }^{2}$ \\ Louis Gritzo, ${ }^{1}$ Ahmed A. Busnaina, ${ }^{2}$ and Ashkan Vaziri ${ }^{2}$ \\ ${ }^{1}$ FM Global, Norwood, MA 02062, USA \\ ${ }^{2}$ Department of Mechanical and Industrial Engineering, Northeastern University, Boston, MA 02115, USA
}

Correspondence should be addressed to Paul Su; pocheng.su@fmglobal.com

Received 10 October 2013; Accepted 12 December 2013; Published 16 January 2014

Academic Editor: Aiying Wang

Copyright (c) 2014 Paul Su et al. This is an open access article distributed under the Creative Commons Attribution License, which permits unrestricted use, distribution, and reproduction in any medium, provided the original work is properly cited.

Contamination of surfaces by nanomaterials can happen due to accidental spillage and release or gradual accumulation during processing or handling. Considering the increasingly wide use of nanomaterials in industry and research labs and also taking into account the diversity of physical and chemical properties of different nanomaterials (such as solubility, aggregation/agglomeration, and surface reactivity), there is a pressing need to define reliable nanomaterial-specific decontamination guidelines. In this paper, we propose and investigate a potential method for surface decontamination of carbon-based nanomaterials using solvent cleaning and wipes. The results show that the removal efficiency for single- and multiwalled carbon nanotubes from silicon wafers sprayed with water-surfactant solutions prior to mechanical wiping is greater than $90 \%$ and $95 \%$, respectively. The need for further studies to understand the mechanisms of nanomaterial removal from surfaces and development of standard techniques for surface decontamination of nanomaterials is highlighted.

\section{Introduction}

Nanomaterials (NMs) are becoming more involved in an increasingly wide range of applications such as in composites, electronics, and automotive, biomedical, and personal care products due to their novel properties and functions [1-3]. Over the last decade, the global production of NMs has experienced a huge growth. For instance, the global production of carbon nanotubes (CNTs) was increased from ca. 280 metric tons in 2006 [4] to ca. 1000 metric tons in 2010 [5] and is anticipated to reach thousands of metric tons in the following decade $[4,6,7]$. The increasing production and application of NMs highlight the need for development of preventive measures and regulations to minimize NM exposure in case of accidental release inside the workplace [2, 8-14].

The potential toxicity of nanomaterials has raised concern about health and safety issues related to the production and use of NMs and their environmental impact as well as potential for contaminated property damage or business interruption due to accidental release of nanomaterials $[2,8-21]$. Preliminary toxicology studies on nanomaterials, including in vitro cytotoxicity [22-24], small animal toxicology [25], and extrapolation of these data to the human scale, reveal the potentially toxic nature of these materials to human biological systems [26-29]. There are several inherent physiochemical factors including NM size, shape, chemical composition, surface charge, surface modifications, and adsorption capacity that can possibly affect the toxicity of nanomaterials [12]. Physical and environmental phenomena such as dissolution, agglomeration, and disagglomeration are the other factors that determine the toxic interaction of nanomaterials with biological systems [28-30]. The three exposure possibilities to NMs are respiration, dermal penetration through skin contact with contaminated surfaces, and digestion [31,32]. Thus, effective decontamination measures for removal of nanomaterials from contaminated surfaces, air, and possibly water supplies are needed. With regard to NM air decontamination, high efficiency particulate air (HEPA) filters can trap air suspended NMs with high efficiency through various filtration mechanisms $[33,34]$. As a first attempt to introduce approaches to remove NMs from contaminated water, Yang et al. reported that the CNTs suspended in the aqueous 
environment can be transformed into large micron size aggregates in the presence of calcium ion $\left(\mathrm{Ca}^{2+}\right)$ and then effectively removed via paper filtration [35]. Concerning the removal of NM from surfaces of solids, the strong attachment of NMs to substrates by van der Waals forces [36-45] and also their increased contact area make it difficult to remove NMs $[46,47]$. Their removal has to be through a physical force that could be applied directly (wipe or brush) or through a fluid (such as ultrasonic, megasonics, or a fluid jet) [4859]. A few studies $[9,34,60-62]$ have provided some basic surface cleaning recommendations for research laboratories and workplace in case of accidental release and spillage of nanomaterials. These recommendations include using vacuum cleaners fitted with HEPA filters on the exhaust to collect the NMs and prevent their dispersion in the air [63]; cleaning the liquid spills by applying absorbent materials/liquid traps $[60,61]$; use of walk-off mats such as a clean room mat or "sticky mats" at access/egress points to limit propagation of particles outside the premises [34, 60,61]; and avoiding the use of energetic methods such as dry sweeping and compressed air for removing the deposited nanomaterials [60-62]. After any visible NM contamination is removed, it is suggested to use wet or electrostatic microfiber cleaning cloths to remove residual NMs from the surfaces while causing minimal dispersion into the air [64].

In this paper, we focus on the surface decontamination of carbon-based NMs which are regarded as one of the most common types of NMs. We propose chemical (solvents, surfactants, etc.) cleaning as a potential method for surface decontamination of carbon-based NMs. In Section 2, we provide an overview of the current state of literature for common categories of solving media and summarize the solubility data for most carbon-based NMs. In Section 3, we discuss our preliminary results on surface decontamination of silicon wafers covered with single- and multiwalled CNTs using a simple wiping procedure and we quantify the removal efficiency of different solvents using scanning microscope imaging of samples before and after cleaning. Finally, conclusions will be derived and the need for further studies will be discussed in Section 4.

\section{Chemical Cleaning}

Chemical cleaning (or solvent cleaning) is used conventionally for the removal of residues, contaminants, or soils deposited on or attached to a substrate surface. The basic concept of chemical cleaning is to dissolve or suspend the contaminants and to eliminate them by the removal of the cleaning media. Studies on the solubility of nanomaterials have shown that many engineered NMs have minimal solubility and dispersibility in water or many common solvents [65-68]. For example, CNTs are shown to be neither soluble nor wettable by water or many other solvents, making them hard to be physically dispersed which in addition to cleaning is critical for obtaining individual CNTs for research and other applications [69-71]. Therefore, various surfactants [65, $69,72-76]$, solvents [77-82], and polymers [83-85], as well as DNA [86-88] have been explored to noncovalently dissolve and disperse CNTs into a liquid phase. Figure 1 summarizes the solubility of single-walled CNT in various solvents as reported in the literature. In general, surfactants (short for surface active agents) are more effective for dissolving higher quantities of single-walled and multiwalled CNTs in water compared to most available solvents. The use of surfactants for the cleaning process is particularly of high interest for a number of reasons; water is a safe and convenient substance and surfactants are cheap, commercially available, and easy to use. The highest solubility is currently reported for an aqueous solution of gum arabic (15\% wt), where $3 \% \mathrm{wt}$. $(\sim 30 \mathrm{mg} / \mathrm{mL})$ solubility was obtained using sonication at $50 \mathrm{~W}$ and $43 \mathrm{kHz}$ for a relatively short duration of 15-20 minutes [85]. We have also explored the available data on solubility of other common carbon-based NMs. In Figure 2, we have summarized the available results on the solubility of $\mathrm{C}_{60}$ fullerene in different solvents. Motivations for studying the solubility of fullerenes in solvents include exploring chemical reactions pathways for fullerene, their purification methods, and extracting higher fullerenes [66, 89-101]. Also, the aqueous solubility of fullerenes with the use of surfactants has been investigated for potential biological applications and the results are included in Figure 2 [102106]. The differences in the reported solubility of fullerenes in a specific solvent in different studies can be attributed to the effects of temperature, illumination, or sonication during the solving process. Extraordinary temperature dependence is observed in the solubility of fullerene $\mathrm{C}_{60}$ in some solvents, reaching its maximum magnitude near $280 \mathrm{~K}$ and decreasing remarkably by increasing the temperature above this value $[97,107,108]$. In addition, there are studies investigating the solubility of higher-order fullerenes [90, 91, 93, 96-98] or combinations of different-order fullerenes [93] in various solvents. Studies performed on the solubility of fullerenes in aqueous media suggest that the solubility rates of fullerene in water-surfactants are several orders of magnitude less than the solubility rates obtained by successful solvents.

Since CNTs are one of the most common carbon-based NMs, we have discussed the efficiency of different solvents for dissolving CNTs in the following sections in more details.

2.1. Surfactants as the Cleaning Media. Surfactants can weaken the strong bond between particles and substrate by reduction of the surface tension, prevention of particle readhesion by creating a repulsive zone between the particles and substrate, and suspension of the particles in the solution by their amphiphilic mechanism [110]. When surfactants are available in adequate concentrations in the solution, they get adsorbed on the surface of CNTs, forming cylindrical micelles or hemimicelles which make CNTs soluble in water [111]. It is necessary that the amount of surfactant dissolved in the aqueous media should be far exceeding the surfactant critical micelle concentration to ensure that enough surfactant molecules can be absorbed onto the surface of the nanotubes to make them suspended and dissolved in water. For example, Sun et al. [76] obtained the optimum concentration of some surfactants for suspending CNTs as equal to $10 \mathrm{mg} / \mathrm{mL}$. However, critical micelle concentrations for these surfactants from the literature are far less than 


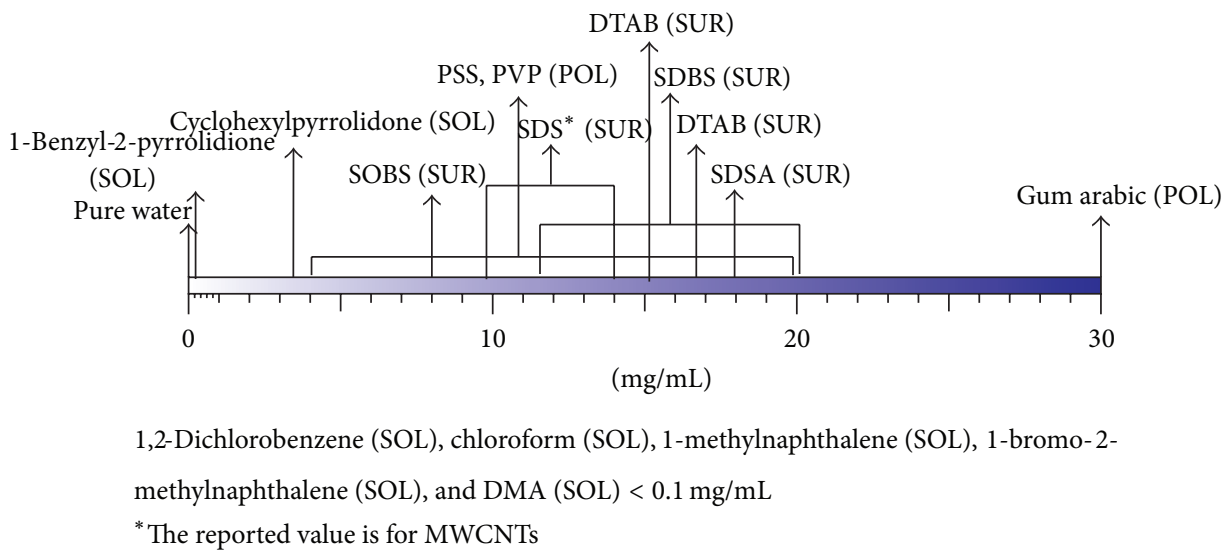

FIGURE 1: High concentration surfactant-, polymer-, and solvent-based suspensions of SWCNT as reported in the literature [69, 72, 75-81].

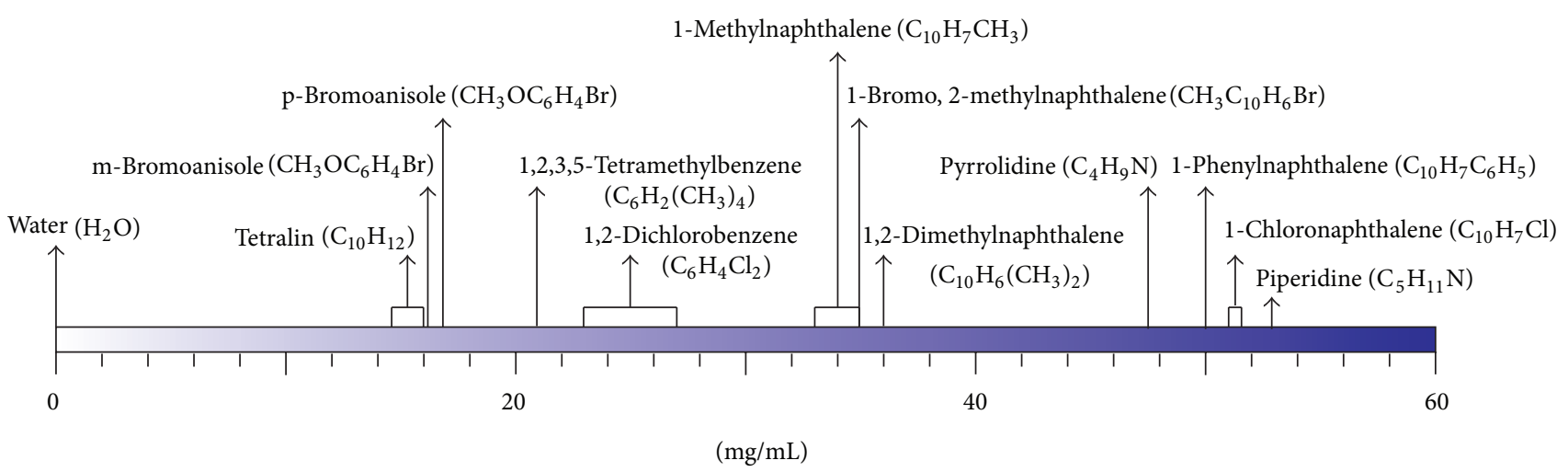

FIGURE 2: Solubility of $\mathrm{C}_{60}$ in the most effective $\mathrm{C}_{60}$ solvents at $298^{\circ} \mathrm{K}$, as reported in the literature $[66,89,99-101,108,109]$.

$10 \mathrm{mg} / \mathrm{mL}$ [76]. In the use of surfactants as the cleaning media combined use of surfactants and mechanical removal might be necessary to fully overcome the adherence of NMs to substrates $[110,112]$.

Islam et al. [69] investigated the solubility of single-walled CNTs in water with different anionic, cationic, and nonionic surfactants by using a long-duration (16-24 hr) sonication procedure. They showed that the anionic surfactants sodium dodecylbenzene sulfonate (NaDDBS) and the close chemical relative, sodium 4-n-octylbenzene sulfonate ( $\mathrm{NaOBS}$ ), had high solubility of single-walled carbon nanotubes, with the solubility of up to $20 \mathrm{mg} / \mathrm{mL}$ and $8 \mathrm{mg} / \mathrm{mL}$ of CNTs, respectively. Using a different solubilization technique, Moore et al. [75] reported the relatively high ability of NaDDBS, and a close relative sodium dodecylsulfonate (SDSA), and sodium dodecyl sulfate (SDS) to individually suspend nanotubes in water [113]. However, of much interest for the purposes of cleaning, they showed that the difunctional block copolymer nonionic surfactants with high molecular weight have high suspendbility (19.2-28.2 mg/mL) but relatively lower individual dispersion quality compared to other surfactants. They concluded that the high dispersion rate of copolymers such as Pluronic F 98 and PEO-PBO-PEO triblock copolymer (EBE) is related to the enhanced steric stabilization by long polymeric groups. The solubility of multiwalled carbon nanotubes in SDS was studied by Zhou et al. [40]. They reported $1.4 \mathrm{wt} \%(14 \mathrm{mg} / \mathrm{mL})$ as the maximum concentration of multiwalled CNTs that can be homogenously dispersed in the aqueous solution. It is noteworthy that the reported quantities for a single surfactant in different studies might be significantly different due to various factors related to the amount of surfactant used, test temperature, mechanical forcing and CNT type and manufacturing method.

2.2. Polymers as the Cleaning Media. Polymers appear as promising options for dissolving CNTs in aqueous media in high concentrations with relatively low agitation $[75,83-$ 85]. O'Connell et al. [84] studied the solution of SWNTs in water by noncovalently associating them with linear polymers such as polyvinylpyrrolidone (PVP) and polystyrene sulfonate (PSS). They suggested that the high concentration solution of CNTs ( $2 \% \mathrm{wt}$., $\sim 20 \mathrm{mg} / \mathrm{mL}$ ) can be obtained by the robust association/wrapping of polymer layers with/around the nanotubes.

2.3. Solvents as the Cleaning Media. The use of solvents as cleaning agents to remove nanomaterials is questionable for a number of reasons. First, many of the solvents proposed to disperse nanotubes have some level of toxicity. Second, the solubility/dispersibility of many of the proposed solvents is 


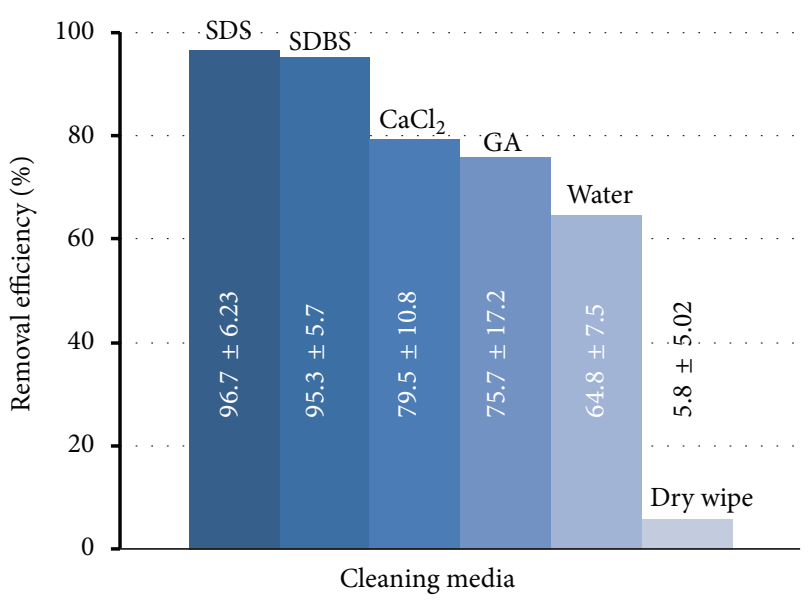

(a)

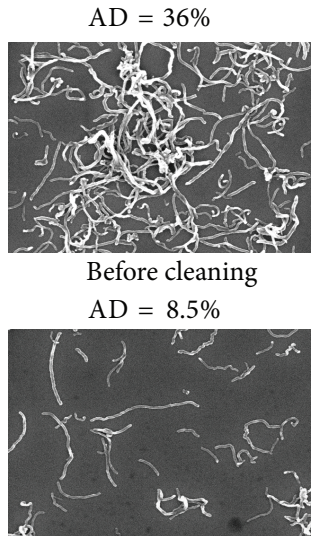

After cleaning (GA)

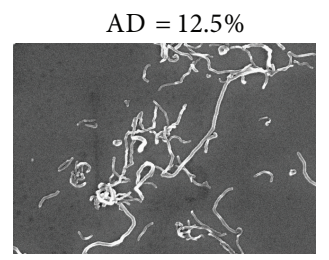

After cleaning (pure water) $\mathrm{AD}=1.5 \%$

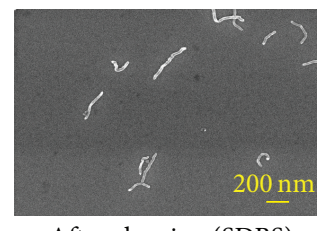

After cleaning (SDBS)

(b)

Figure 3: (a) MWCNT removal efficiency of SDS, SDBS, $\mathrm{CaCl}_{2}$, gum arabic (GA), water, and dry wiping as discussed in Section 3. (b) Sample SEM image of the surface of multiwalled carbon nanotubes deposited silicon wafers before cleaning $(\mathrm{AD}=36 \%)$ and after wipe cleaning with pure water $(\mathrm{AD}=12.5 \%)$, gum Arabic $(\mathrm{AD}=8.5 \%)$, and $\mathrm{SDBS}$ surfactant $(\mathrm{AD}=1.5 \%)$. The average precleaning areal density was approximately $34 \%$ for all samples.

below $0.1 \mathrm{mg} / \mathrm{mL}$, far less than the solubility of surfactants. Parra-Vasquez et al. [81] investigated the solubility of SWNTs obtained by different methods of production in superacids (e.g., fuming sulfuric and chlorosulfonic acids) and showed that high concentrations ( $>100 \mathrm{mg} / \mathrm{mL}$ ) of SWNTs are spontaneously dispersed in acids within minutes. However, the use of acids as the cleaning media in the cleanup process does not seem reasonable because of the hazards in handling and usage and removal of acids and also the potential damage to the substrate.

\section{Experimental Investigation: Removal Efficiency of CNT Chemical Cleaning}

In this section, experimental investigations were performed to assess the removal efficiency of CNTs deposited on the surface of silicon wafers using different cleaning media. The CNTs used for this study were combustion chemical vapor deposition (CCVD) grown, acid purified carbon nanotubes dispersed in polyvinylpyrrolidone (PVP) surfactant. The average length and diameter of the MWCNTs used in this study were measured to be $250 \mathrm{~nm}$ and $15 \mathrm{~nm}$, respectively. The averaged length and diameter of SWNCTs were $200 \mathrm{~nm}$ and $1.2 \mathrm{~nm}$, respectively. In the experiments, carbon nanotubes in the form of pristine liquid solution were deposited on surface of silicon wafers ((111) orientation, nitrogen/phosphorus doped, P/E surface, and with mechanical grading) using the spin coating process. The wafers were $3^{\prime \prime}$ in diameter and the spin coating was performed for $1 \mathrm{~min}$ at 3000 RPM. After spin coating, the CNT deposited wafers were heated at $105^{\circ} \mathrm{C}$ for $90 \mathrm{sec}$. in order to dry the wafer surface completely. A total number of 30 images with equal magnification and resolution were taken from different spots of each wafer surface using scanning electron microscope (SEM) imaging. The CNT surface aerial concentration for each image was then determined using an image processing program incorporated in MATLAB software. Average CNT aerial density from 30 different images of each wafer was obtained and used in the analysis. The average aerial density of the wafers, denoted by $\mathrm{AD}$, was approximately $34 \%$ for SWCNTs and $36 \%$ for MWCNTs after the spin coating.

First, we have assessed the multiwalled CNT removal efficiency of two surfactants (i.e., SDBS (sodium dodecylbenzene sulfonate) and SDS (sodium dodecyl sulfate)), one polymer (gum arabic), one mineral salt (calcium chloride), and pure water in a simple wipe cleaning method. The concentrations of SDBS, SDS, $\mathrm{CaCl}_{2}$, and gum arabic (GA) were $1.5 \%, 4 \%, 11 \%$, and $10 \% \mathrm{wt}$, respectively. The mineral salt calcium chloride was specifically chosen since it was shown to be capable of transforming dispersed CNT in aqueous environment into aggregates [35]. The CNT-coated wafers were first treated by different cleaning media and then cleaned with a piece of nonwoven polyester/cellulose fabric. In the experiments, first the cleaning medium was sprayed on the surface of the wafer. After 2 minutes, the wafer was manually wiped once unidirectionally. The estimated hand pressure and wiping duration were $2 \mathrm{kPa}$ and $5 \mathrm{sec}$., respectively. The wafer was dried using nitrogen gas after the cleaning. After cleaning, the wafers were imaged using SEM and the average final area density for each wafer was obtained by postprocessing the images as explained above. The removal efficiency was defined as the difference between the initial and the final average CNT aerial densities. Figure 3(a) shows the quantitative comparison of MWNT surface removal efficiency by different cleaning media used in this study. Figure 3(b) shows the SEM images of MWCNT-coated wafer surfaces before and after cleaning using different cleaning media. The two surfactants used in the experiments, SDS and SDBS, showed the highest MWCNT removal rates among all the solvent cleaning media with removal efficiency greater than $95 \%$. The high removal efficiency in using the surfactant as the cleaning media can be attributed to the role of 


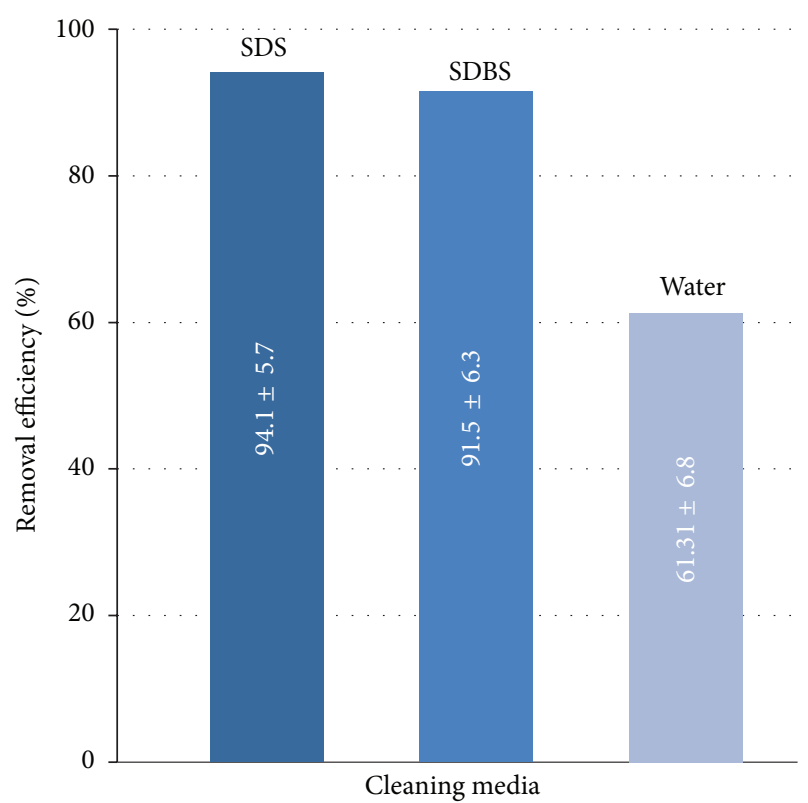

(a)
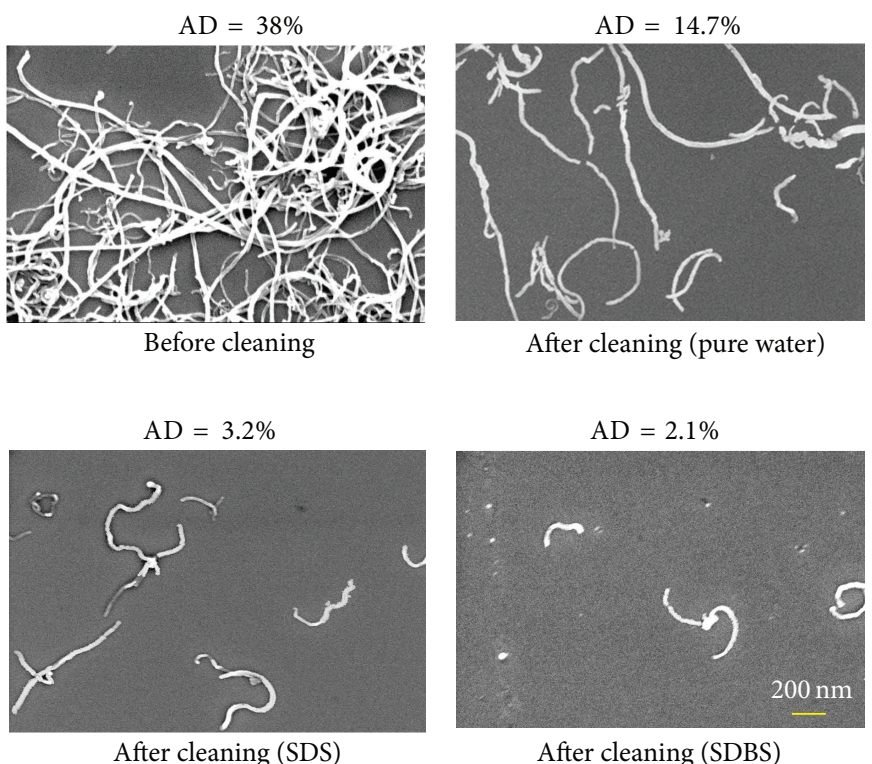

(b)

FIGURE 4: (a) SWCNT removal efficiency of SDS, SDBS and water as discussed in Section 3. (b) Sample SEM image of the surface of SWNTs deposited silicon wafers before cleaning $(\mathrm{AD}=38 \%)$ and after wipe cleaning with pure water $(\mathrm{AD}=14.7 \%)$, SDBS $(\mathrm{AD}=3.2 \%)$, and $\mathrm{SDS}$ surfactant $(\mathrm{AD}=2.1 \%)$. The average precleaning areal density was approximately $36 \%$ for all samples.

surfactant micelles in suspending the CNTs in aqueous media and increasing the soaking ability of water by decreasing the water surface tension. Pure water has the removal efficiency of almost $65 \%$ on the silicon wafer substrate. Gum arabic and $\mathrm{CaCl}_{2}$ have comparable removal efficiency of approximately $76 \%$ and $80 \%$, respectively, standing between the removal efficiency of pure water and that of surfactants solutions.

As the next step, we measured the single-walled CNT removal efficiency of two surfactants (i.e., SDBS (sodium dodecylbenzene sulfonate) and SDS (sodium dodecyl sulfate)), and pure water in the same wipe cleaning method. The two surfactants were chosen since they showed the highest efficiency for the removal of MWCNTs from the surface of silicon wafer in the last section. The same deposition and wiping methods were used. In Figure 4(a) a quantitative comparison of SWNT surface removal efficiency by different cleaning media is given. The two surfactants showed high SWCNT removal capability with efficiency greater than $90 \%$. Wiping after pure water spray resulted in a removal efficiency of approximately $61 \%$. Figure $4(\mathrm{~b})$ shows sample SEM images of SWCNT-coated wafer surfaces before and after cleaning.

\section{Conclusions}

We proposed solvent cleaning as a technique for surface decontamination of carbon-based NMs such as CNTs, which can potentially be used for removal of nanomaterial adhered to surfaces caused by unwanted spillage and release or the gradual accumulation during the processing or handling. The role of cleaning media (i.e., surfactants, solvents, etc.) in facilitating the mechanical removal of single- and multiwalled CNTs from contaminated surfaces was discussed.
The challenges associated with this technique include the high levels of agglomeration of CNTs and extremely low solubility in water and many common solvents, which tend to lower the efficiency of this method. Based on our pilot study presented in Section 3, the removal efficiency of singleand multiwalled carbon nanotubes using two different watersurfactant solutions from a highly smooth surface of a silicon wafer through wiping is greater than $90 \%$ and $95 \%$, respectively. The higher removal efficiency for multiwalled carbon nanotubes can be attributed to the larger value of the binding energy density holding the nanotube aggregates together for MWCNTs compared to SWCNTs [114]. Surfactants are economical, commercially available, and easy to use. These factors make surfactants a good candidate for the removal of CNTs deposited on surfaces. However, more studies are needed to determine the effectiveness of CNT removal using the solvent cleaning technique for CNTs obtained by various production methods, with different chemical modifications or attached on different substrates.

\section{Conflict of Interests}

The authors declare that there is no conflict of interests regarding the publication of this article.

\section{Acknowledgments}

The authors thank Dr. Sivasubramanian Somu for the insightful discussion and Ms. Joy McNally for assistance in providing the journal articles referenced in this work. This work was supported in part by FM Global and by the U.S. Air Force 
Office of Scientific Research under AFOSR YIP Grant Award, \#FA FA9550-10-1-0145, under the technical supervision of Dr. Joycelyn Harrison. The authors also acknowledge the support of the Center of High-Rate Nanomanufacturing at Northeastern University for the experimental part of the study.

\section{References}

[1] The project on emerging nanotechnologies, Nanotechnology Consumer Products Inventory, http://www.nanotechproject .org/inventories/consumer/analysis_draft/.

[2] A. Dowling, Nanoscience and Nanotechnologies: Opportunities and Uncertainties, The Royal Society and the Royal Academy of Engineering, London, UK, 2004.

[3] S. S. Oh, D. H. Kim, M.-W. Moon et al., "Indium nanowires synthesized at an ultrafast rate," Advanced Materials, vol. 20, no. 6, pp. 1093-1098, 2008.

[4] S. Glotzer, International Assessment of Research and Development in Simulation-Based Engineering and Science, Imperial College Press, London, UK, 2010.

[5] "News briefing," Nature, vol. 461, pp. 702-703, 2009.

[6] Progress and perspectives in the carbon nanotube world, http://www.azonano.com/details.asp?articleID=2619.

[7] A. M. Thayer, "Carbon nanotubes by the metric ton: anticipating new commercial applications, producers increase capacity," Chemical \& Engineering News, vol. 85, no. 46, pp. 29-38, 2007.

[8] National Institute for Occupational Safety and Health-NIOSH, "Approaches to safe nanotechnology-managing the health and safety concerns associated with engineered nanomaterials," 2009, http://www.cdc.gov/niosh/docs/2009-125/.

[9] US Department of Energy, "Approaches to Nanomaterial ES\&H," Department of Energy, Nanoscale Science Centers, 2008, http://science.energy.gov/ /media/bes/pdf/doe_nsrc_ approach_to_nanomaterial_esh.pdf.

[10] "Report, L.s.E.R.T., Nanotechnology: Recent Developments, Risks and Opportunities," 2007, http://www.lloyds.com/ / media/Lloyds/Archive/Lloyds\%20Market\%20Gallery/Lloyds\% 20Market\%20Gallery/ER_Nanotechnology_Report.pdf.

[11] A. Hett, Nanotechnology: Small Size-Large Impact, Risk Dialogue Series, Swiss Reinsurance, Zurich, Switzerland, 2005.

[12] US Environmental Protection Agency-EPA, Nanotechnology white paper, 2007, http://www.epa.gov/osa/pdfs/nanotech/epananotechnology-whitepaper-0207.pdf.

[13] National Institute for Occupational Safety and Health-NIOSH, "Progress toward safe nanotechnology in the workplace," 2007.

[14] A. C. Lin, "Size matters: regulating nanotechnology," Harvard Environmental Law Review, vol. 31, no. 2, pp. 349-408, 2007.

[15] P. Su, It Is a Small World, Reason, FM Global Research, Norwood, Mass, USA, 2010.

[16] National Institute for Occupational Safety and Health-NIOSH, "Interim guidance for worker medical screening, hazard surveillance pertaining to engineered nanoparticles," 2009, http://www.cdc.gov/niosh/docs/2009-116/.

[17] Y. Ju-Nam and J. R. Lead, "Manufactured nanoparticles: an overview of their chemistry, interactions and potential environmental implications," Science of the Total Environment, vol. 400, no. 1-3, pp. 396-414, 2008.

[18] National Institute for Occupational Safety and Health-NIOSH, Strategic plan for NIOSH nanotechnology research and guidance, http://www.cdc.gov/niosh/docs/2010-105/.
[19] C. A. Poland, R. Duffin, I. Kinloch et al., "Carbon nanotubes introduced into the abdominal cavity of mice show asbestoslike pathogenicity in a pilot study," Nature Nanotechnology, vol. 3, no. 7, pp. 423-428, 2008.

[20] V. J. Feron, J. H. E. Arts, C. F. Kuper, P. J. Slootweg, and R. A. Woutersen, "Health risks associated with inhaled nasal toxicants," Critical Reviews in Toxicology, vol. 31, no. 3, pp. 313347, 2001.

[21] A. D. Maynard, P. A. Baron, M. Foley, A. A. Shvedova, E. R. Kisin, and V. Castranova, "Exposure to carbon nanotube material: aerosol release during the handling of unrefined single-walled carbon nanotube material," Journal of Toxicology and Environmental Health A, vol. 67, no. 1, pp. 87-107, 2004.

[22] G. Jia, H. Wang, L. Yan et al., "Cytotoxicity of carbon nanomaterials: single-wall nanotube, multi-wall nanotube, and fullerene," Environmental Science \& Technology, vol. 39, no. 5, pp. 13781383, 2005.

[23] C. Kirchner, T. Liedl, S. Kudera et al., "Cytotoxicity of colloidal CdSe and CdSe/ZnS nanoparticles," Nano Letters, vol. 5, no. 2, pp. 331-338, 2005.

[24] N. Lewinski, V. Colvin, and R. Drezek, "Cytotoxicity of nanopartides," Small, vol. 4, no. 1, pp. 26-49, 2008.

[25] C.-W. Lam, J. T. James, R. McCluskey, and R. L. Hunter, "Pulmonary toxicity of single-wall carbon nanotubes in mice 7 and 90 days after intractracheal instillation," Toxicological Sciences, vol. 77, no. 1, pp. 126-134, 2004.

[26] S. F. Hansen, E. S. Michelson, A. Kamper, P. Borling, F. StuerLauridsen, and A. Baun, "Categorization framework to aid exposure assessment of nanomaterials in consumer products," Ecotoxicology, vol. 17, no. 5, pp. 438-447, 2008.

[27] Z. D. Ok, J. C. Benneyan, and J. A. Isaacs, "Nanotechnology environmental, health, and safety issues: brief literature review since 2000," in Proceedings of the IEEE International Symposium on Sustainable Systems and Technology (ISSST '09), pp. 1-5, Phoenix, Ariz, USA, May 2009.

[28] P. J. A. Borm, D. Robbins, S. Haubold et al., “The potential risks of nanomaterials: a review carried out for ECETOC," Particle and Fibre Toxicology, vol. 3, no. 1, article 11, 2006.

[29] R. Hardman, "A toxicologic review of quantum dots: toxicity depends on physicochemical and environmental factors," Environmental Health Perspectives, vol. 114, no. 2, pp. 165-172, 2006.

[30] J. Liu, D. M. Aruguete, M. Murayama, and M. F. Hochella Jr., "Influence of size and aggregation on the reactivity of an environmentally and industrially relevant nanomaterial (PbS)," Environmental Science \& Technology, vol. 43, no. 21, pp. 81788183, 2009.

[31] R. J. Aitken, K. S. Creely, and C. L. Tran, Nanoparticles: An Occupational Hygiene Review, Institute of Occupational Medicine, Edinburgh, UK, 2004.

[32] AFSSET, "Nanomaterials: Effects on the Environment and Human Health," 2006, http://www.afssa.fr/ET/DocumentsET/ afsset-summary-nanomaterials.pdf.

[33] L. Golanski, A. Guiot, and F. Tardif, "Efficiency of fibrous filters and personal protective equipments against nanoaerosols," Tech. Rep., Euripean Strategy for Nanosafety, 2008.

[34] AFSSET, "Nanomaterials and occupational safety," 2008, http:// www.afssa.fr/ET/DocumentsET/08_07_ED_Nanomateriaux_2_ Avis_EV.pdf.

[35] S.-T. Yang, H. Wang, Y. Wang, Y. Wang, H. Nie, and Y. Liu, "Removal of carbon nanotubes from aqueous environment with filter paper," Chemosphere, vol. 82, no. 4, pp. 621-626, 2011. 
[36] T. S. Chow, "Size-dependent adhesion of nanoparticles on rough substrates," Journal of Physics Condensed Matter, vol. 15, no. 2, pp. L83-L87, 2003.

[37] S. Joo and D. F. Baldwin, "Adhesion mechanisms of nanoparticle silver to substrate materials: identification," Nanotechnology, vol. 21, no. 5, Article ID 055204, 2010.

[38] J. D. Whittaker, E. D. Minot, D. M. Tanenbaum, P. L. McEuen, and R. C. Davis, "Measurement of the adhesion force between carbon nanotubes and a silicon dioxide substrate," Nano Letters, vol. 6, no. 5, pp. 953-957, 2006.

[39] L. Qu, L. Dai, M. Stone, Z. Xia, and L. W. Zhong, "Carbon nanotube arrays with strong shear binding-on and easy normal lifting-off," Science, vol. 322, no. 5899, pp. 238-242, 2008.

[40] W. Zhou, Y. Huang, B. Liu et al., "Adhesion between carbon nanotubes and substrate: mimicking the gecko foot-hair," Nano, vol. 2, no. 3, pp. 175-179, 2007.

[41] B. Yurdumakan, N. R. Raravikar, P. M. Ajayan, and A. Dhinojwala, "Synthetic gecko foot-hairs from multiwalled carbon nanotubes," Chemical Communications, no. 30, pp. 3799-3801, 2005.

[42] S. Hu, T. H. Kim, J. G. Park, and A. A. Busnaina, "Effect of different deposition mediums on the adhesion and removal of particles," Journal of the Electrochemical Society, vol. 157, no. 6, pp. H662-H665, 2010.

[43] D. S. Rimai, D. J. Quesnel, and A. A. Busnaina, “The adhesion of dry particles in the nanometer to micrometer-size range," Colloids and Surfaces A, vol. 165, no. 1-3, pp. 3-10, 2000.

[44] A. A. Busnaina and T. Elsawy, "The effect of relative humidity on particle adhesion and removal," The Journal of Adhesion, vol. 74, no. 1-4, pp. 391-409, 2000.

[45] J. Tang and A. A. Busnaina, "The effect of time and humidity on particle adhesion and removal," The Journal of Adhesion, vol. 74, no. 1-4, pp. 411-419, 2000.

[46] S. Krishnan, A. A. Busnaina, D. S. Rimai, and L. P. Demejo, “The adhesion-induced deformation and the removal of submicrometer particles," Journal of Adhesion Science and Technology, vol. 8, no. 11, pp. 1357-1370, 1994.

[47] A. Busnaina, J. Taylor, and I. Kashkoush, "Measurement of the adhesion and removal forces of submicrometer particles on silicon substrates," Journal of Adhesion Science and Technology, vol. 7, no. 5, pp. 441-455, 1993.

[48] P. Karimi, T. Kim, J. Aceros, J. Park, and A. A. Busnaina, "The removal of nanoparticles from sub-micron trenches using megasonics," Microelectronic Engineering, vol. 87, no. 9, pp. 1665-1668, 2010.

[49] K. Bakhtari, R. O. Guldiken, P. Makaram, A. A. Busnaina, and J.-G. Park, "Experimental and numerical investigation of nanoparticle removal using acoustic streaming and the effect of time," Journal of the Electrochemical Society, vol. 153, no. 9, pp. G846-G850, 2006.

[50] K. Bakhtari, R. O. Guldiken, A. A. Busnaina, and J.-G. Park, "Experimental and analytical study of submicrometer particle removal from deep trenches," Journal of the Electrochemical Society, vol. 153, no. 9, pp. C603-C607, 2006.

[51] O. Guldiken, K. Bakhtari, A. Busnaina, and J. Park, "Metrology and removal of nanoparticles from 500 micron deep trenches," Solid State Phenomena, vol. 103-104, pp. 137-140, 2005.

[52] N. Moumen and A. A. Busnaina, "Removal of submicrometre alumina particles from silicon oxide substrates," Surface Engineering, vol. 17, no. 5, pp. 422-424, 2001.
[53] A. A. Busnaina and F. Dai, "The removal of submicron particles in liquid-based cleaning," The Journal of Adhesion, vol. 67, no. 1-4, pp. 181-193, 1998.

[54] A. A. Busnaina and G. W. Gale, "Removal of silica particles from silicon substrates using megasonic cleaning," Particulate Science and Technology, vol. 15, no. 3-4, pp. 361-369, 1997.

[55] G. W. Gale and A. A. Busnaina, "Removal of particulate contaminants using ultrasonics and megasonics: a review," Particulate Science and Technology, vol. 13, no. 3-4, pp. 197-211, 1995.

[56] D. S. Rimai and A. A. Busnaina, "Adhesion and removal of particles from surfaces," Particulate Science and Technology, vol. 13, no. 3-4, pp. 249-270, 1995.

[57] A. A. Busnaina, I. I. Kashkoush, and G. W. Gale, "An experimental study of megasonic cleaning of silicon wafers," Journal of the Electrochemical Society, vol. 142, no. 8, pp. 2812-2817, 1995.

[58] A. Busnaina and I. Kashkoush, "The effect of time, temperature and particle size on submicron particle removal using ultrasonic cleaning," Chemical Engineering Communications, vol. 125, no. 1, pp. 47-61, 1993.

[59] I. Kashkoush and A. Busnaina, "Submicron particle removal using ultrasonic cleaning," Particulate Science and Technology, vol. 11, no. 1-2, pp. 11-24, 1993.

[60] British Standard Institute, "Nanotechnologies-part 1: good practices guide for specifying manufactured nanomaterials," 2007, http://www3.imperial.ac.uk/pls/portallive/docs/1/34683697 .PDF.

[61] British Standard Institute, "Nanotechnologies—part 2: guide to safe handling and disposal of manufactured nanomaterials," 2007, http://www3.imperial.ac.uk/pls/portallive/docs/1/ 34683696.PDF.

[62] BAUA, "Guidance for the handling and use of nanomaterials at the workplace," 2007.

[63] M. Klenke, "First results for safe procedures for handling nanoparticles," Tech. Rep., European Strategy for Nanosafety, 2008.

[64] D. Fleury, J. A. S. Bomfim, S. Metz, J. X. Bouillard, and J.-M. Brignon, "Nanoparticle risk management and cost evaluation: a general framework," Journal of Physics, vol. 304, no. 1, Article ID 012084, 2011.

[65] L. Vaisman, H. D. Wagner, and G. Marom, "The role of surfactants in dispersion of carbon nanotubes," Advances in Colloid and Interface Science, vol. 128-130, pp. 37-46, 2006.

[66] R. S. Ruoff, D. S. Tse, R. Malhotra, and D. C. Lorents, "Solubility of $\mathrm{C}_{60}$ in a variety of solvents," The Journal of Physical Chemistry, vol. 97, no. 13, pp. 3379-3383, 1993.

[67] W. W. Yu, E. Chang, R. Drezek, and V. L. Colvin, "Water-soluble quantum dots for biomedical applications," Biochemical and Biophysical Research Communications, vol. 348, no. 3, pp. 781786, 2006.

[68] B. L. Frankamp, N. O. Fischer, R. Hong, S. Srivastava, and V. M. Rotello, "Surface modification using cubic silsesquioxane ligands. Facile synthesis of water-soluble metal oxide nanoparticles," Chemistry of Materials, vol. 18, no. 4, pp. 956-959, 2006.

[69] M. F. Islam, E. Rojas, D. M. Bergey, A. T. Johnson, and A. G. Yodh, "High weight fraction surfactant solubilization of singlewall carbon nanotubes in water," Nano Letters, vol. 3, no. 2, pp. 269-273, 2003.

[70] S.-W. Kim, S. Kim, J. B. Tracy, A. Jasanoff, and M. G. Bawendi, "Phosphine oxide polymer for water-soluble nanoparticles," Journal of the American Chemical Society, vol. 127, no. 13, pp. 4556-4557, 2005. 
[71] C. X. Song, V. Labhasetwar, H. Murphy et al., "Formulation and characterization of biodegradable nanoparticles for intravascular local drug delivery," Journal of Controlled Release, vol. 43, no. 2-3, pp. 197-212, 1997.

[72] J. Yu, N. Grossiord, C. E. Koning, and J. Loos, "Controlling the dispersion of multi-wall carbon nanotubes in aqueous surfactant solution," Carbon, vol. 45, no. 3, pp. 618-623, 2007.

[73] H. Wang, W. Zhou, D. L. Ho et al., "Dispersing single-walled carbon nanotubes with surfactants: a small angle neutron scattering study," Nano Letters, vol. 4, no. 9, pp. 1789-1793, 2004.

[74] O. Matarredona, H. Rhoads, Z. Li, J. H. Harwell, L. Balzano, and D. E. Resasco, "Dispersion of single-walled carbon nanotubes in aqueous solutions of the anionic surfactant NaDDBS," The Journal of Physical Chemistry B, vol. 107, no. 48, pp. 13357-13367, 2003.

[75] V. C. Moore, M. S. Strano, E. H. Haroz et al., "Individually suspended single-walled carbon nanotubes in various surfactants," Nano Letters, vol. 3, no. 10, pp. 1379-1382, 2003.

[76] Z. Sun, V. Nicolosi, D. Rickard, S. D. Bergin, D. Aherne, and J. N. Coleman, "Quantitative evaluation of surfactantstabilized single-walled carbon nanotubes: dispersion quality and its correlation with zeta potential," The Journal of Physical Chemistry C, vol. 112, no. 29, pp. 10692-10699, 2008.

[77] J. L. Bahr, E. T. Mickelson, M. J. Bronikowski, R. E. Smalley, and J. M. Tour, "Dissolution of small diameter single-wall carbon nanotubes in organic solvents?" Chemical Communications, no. 2, pp. 193-194, 2001.

[78] B. J. Landi, H. J. Ruf, J. J. Worman, and R. P. Raffaelle, "Effects of alkyl amide solvents on the dispersion of single-wall carbon nanotubes," The Journal of Physical Chemistry B, vol. 108, no. 44, pp. 17089-17095, 2004.

[79] S. D. Bergin, Z. Sun, P. Streich, J. Hamilton, and J. N. Coleman, "New solvents for nanotubes: approaching the dispersibility of surfactants," The Journal of Physical Chemistry C, vol. 114, no. 1, pp. 231-237, 2010.

[80] K. D. Ausman, R. Piner, O. Lourie, R. S. Ruoff, and M. Korobov, "Organic solvent dispersions of single-walled carbon nanotubes: toward solutions of pristine nanotubes," The Journal of Physical Chemistry B, vol. 104, no. 38, pp. 8911-8915, 2000.

[81] A. N. G. Parra-Vasquez, N. Behabtu, M. J. Green et al., "Spontaneous dissolution of ultralong single-and multiwalled carbon nanotubes," ACS Nano, vol. 4, no. 7, pp. 3969-3978, 2010.

[82] S. D. Bergin, V. Nicolosi, P. V. Streich et al., "Towards solutions of single-walled carbon nanotubes in common solvents," Advanced Materials, vol. 20, no. 10, pp. 1876-1881, 2008.

[83] J. N. Coleman, A. B. Dalton, S. Curran et al., "Phase separation of carbon nanotubes and turbostratic graphite using a functional organic polymer," Advanced Materials, vol. 12, no. 3, pp. 213-216, 2000.

[84] M. J. O’Connell, P. Boul, L. M. Ericson et al., "Reversible watersolubilization of single-walled carbon nanotubes by polymer wrapping," Chemical Physics Letters, vol. 342, no. 3-4, pp. 265271, 2001.

[85] R. Bandyopadhyaya, E. Nativ-Roth, O. Regev, and R. Yerushalmi-Rozen, "Stabilization of individual carbon nanotubes in aqueous solutions," Nano Letters, vol. 2, no. 1, pp. 25-28, 2002.

[86] R. Haggenmueller, S. S. Rahatekar, J. A. Fagan et al., "Comparison of the quality of aqueous dispersions of single wall carbon nanotubes using surfactants and biomolecules," Langmuir, vol. 24, no. 9, pp. 5070-5078, 2008.
[87] S. Badaire, C. Zakri, M. Maugey et al., "Liquid crystals of DNAstabilized carbon nanotubes," Advanced Materials, vol. 17, no. 13, pp. 1673-1676, 2005.

[88] M. Zheng, A. Jagota, M. S. Strano et al., "Structure-based carbon nanotube sorting by sequence-dependent DNA assembly," Science, vol. 302, no. 5650, pp. 1545-1548, 2003.

[89] W. A. Scrivens and J. M. Tour, "Potent solvents for $\mathrm{C}_{60}$ and their utility for the rapid acquisition of ${ }^{13} \mathrm{C}$ NMR data for fullerenes," Journal of the Chemical Society, Chemical Communications, no. 15, pp. 1207-1209, 1993.

[90] M. T. Beck, "Solubility and molecular state of $\mathrm{C}_{60}$ and $\mathrm{C}_{70}$ in solvents and solvent mixtures," Pure and Applied Chemistry, vol. 70, no. 10, pp. 1881-1887, 1998.

[91] T. Tomiyama, S. Uchiyama, and H. Shinohara, "Solubility and partial specific volumes of $\mathrm{C}_{60}$ and $\mathrm{C}_{70}$," Chemical Physics Letters, vol. 264, no. 1-2, pp. 143-148, 1997.

[92] V. N. Bezmel'nitsyn, A. V. Eletskii, and M. V. Okun, "Fullerenes in solutions," Physics-Uspekhi, vol. 41, no. 11, article 1091, 1998.

[93] K. N. Semenov, N. A. Charykov, V. A. Keskinov, A. K. Piartman, A. A. Blokhin, and A. A. Kopyrin, "Solubility of light fullerenes in organic solvents," Journal of Chemical \& Engineering Data, vol. 55, no. 1, pp. 13-36, 2010.

[94] Y. Marcus, A. L. Smith, M. V. Korobov, A. L. Mirakyan, N. V. Avramenko, and E. B. Stukalin, "Solubility of $\mathrm{C}_{60}$ fullerene," The Journal of Physical Chemistry B, vol. 105, no. 13, pp. 2499-2506, 2001.

[95] N. Sivaraman, R. Dhamodaran, I. Kaliappan, T. G. Srinivasan, P. R. Vasudeva Rao, and C. K. Mathews, "Solubility of $\mathrm{C}_{60}$ in organic solvents," The Journal of Organic Chemistry, vol. 57, no. 22, pp. 6077-6079, 1992.

[96] N. Sivaraman, R. Dhamodaran, I. Kaliappan, T. G. Srinivasan, V. P. R. Rao, and C. K. Mathews, "Solubility of $\mathrm{C}_{70}$ in organic solvents," Fullerene Science and Technology, vol. 2, no. 3, pp. 233246, 1994.

[97] X. Zhou, J. Liu, Z. Jin, Z. Gu, Y. Wu, and Y. Sun, "Solubility of fullerene $\mathrm{C}_{60}$ and $\mathrm{C}_{70}$ in toluene, $\mathrm{O}$-xylene and carbon disulfide at various temperatures," Fullerene Science and Technology, vol. 5, no. 1, pp. 285-290, 1997.

[98] M. V. Korobov, A. L. Mirakyan, N. V. Avramenko, G. Olofsson, A. L. Smith, and R. S. Ruoff, "Calorimetric studies of solvates of $\mathrm{C}_{60}$ and $\mathrm{C}_{70}$ with aromatic solvents," The Journal of Physical Chemistry B, vol. 103, no. 8, pp. 1339-1346, 1999.

[99] D. Heymann, "Solubility of $\mathrm{C}_{60}$ in alcohols and alkanes," Carbon, vol. 34, no. 5, pp. 627-631, 1996.

[100] S. Talukdar, P. Pradhan, and A. Banerji, "Electron donoracceptor interactions of $\mathrm{C}_{60}$ with $\mathrm{n}$-and $\pi$-donors : a rational approach towards its solubility," Fullerene Science and Technology, vol. 5, no. 3, pp. 547-557, 1997.

[101] N. V. Avramenko, E. B. Stukalin, and M. V. Korobov, “Thermodynamic properties of the molecular complexes of $\mathrm{C}_{60}$ with monosubstituted naphthalenes," Journal of Thermal Analysis and Calorimetry, vol. 82, no. 1, pp. 125-127, 2005.

[102] I. Ramakanth and A. Patnaik, "Characteristics of solubilization and encapsulation of fullerene $\mathrm{C}_{60}$ in non-ionic Triton X-100 micelles," Carbon, vol. 46, no. 4, pp. 692-698, 2008.

[103] A. Beeby, J. Eastoe, and R. K. Heenan, "Solubilisation of $\mathrm{C}_{60}$ in aqueous micellar solution," Journal of the Chemical Society, Chemical Communications, no. 2, pp. 173-175, 1994.

[104] Y. N. Yamakoshi, T. Yagami, K. Fukuhara, S. Sueyoshi, and N. Miyata, "Solubilization of fullerenes into water with polyvinylpyrrolidone applicable to biological tests," Journal of 
the Chemical Society, Chemical Communications, no. 4, pp. 517$518,1994$.

[105] D. T. Lai, M. A. Neumann, M. Matsumoto, and J. Sunamoto, "Complexation of $\mathrm{C}_{60}$ fullerene with cholesteryl group-bearing pullulan in aqueous medium," Chemistry Letters, vol. 29, no. 1, pp. 64-65, 2000.

[106] H. Hungerbuehler, D. M. Guldi, and K. D. Asmus, "Incorporation of $\mathrm{C}_{60}$ into artificial lipid membranes," Journal of the American Chemical Society, vol. 115, no. 8, pp. 3386-3387, 1993.

[107] R. S. Ruoff, R. Malhotra, D. L. Huestis, D. S. Tse, and D. C. Lorents, "Anomalous solubility behaviour of $\mathrm{C}_{60}$ " Nature, vol. 362, no. 6416, pp. 140-141, 1993.

[108] R. J. Doome, S. Dermaut, A. Fonseca, M. Hammida, and J. B. Nagy, "New evidences for the anomalous temperaturedependent solubility of $\mathrm{C}_{60}$ and $\mathrm{C}_{70}$ fullerenes in various solvents," Fullerene Science and Technology, vol. 5, no. 7, pp. 1593-1606, 1997.

[109] M. T. Beck, G. Mandi, and S. Keki, "Solubility and molecular state of $\mathrm{C}_{60}$ in organic solvents," in Recent Advances in the Chemistry and Physics of Fullerenes and Related Materials. 187th Electrochemical Society Meeting, pp. 1510-1518, Electrochemical Society, Reno, Nev, USA, 1995.

[110] D. Ng, P. Y. Huang, Y. R. Jeng, and H. Liang, "Nanoparticle removal mechanisms during post-CMP cleaning," Electrochemical and Solid-State Letters, vol. 10, no. 8, pp. H227-H231, 2007.

[111] K. Yurekli, C. A. Mitchell, and R. Krishnamoorti, "Small-angle neutron scattering from surfactant-assisted aqueous dispersions of carbon nanotubes," Journal of the American Chemical Society, vol. 126, no. 32, pp. 9902-9903, 2004.

[112] D. Ng, S. Kundu, M. Kulkarni, and H. Liang, "Role of surfactant molecules in post-CMP cleaning," Journal of the Electrochemical Society, vol. 155, no. 2, pp. H64-H68, 2008.

[113] M. J. O'Connell, S. H. Bachilo, C. B. Huffman et al., "Band gap fluorescence from individual single-walled carbon nanotubes," Science, vol. 297, no. 5581, pp. 593-596, 2002.

[114] Y. Y. Huang and E. M. Terentjev, "Dispersion of carbon nanotubes: mixing, sonication, stabilization, and composite properties," Polymers, vol. 4, no. 1, pp. 275-295, 2012. 

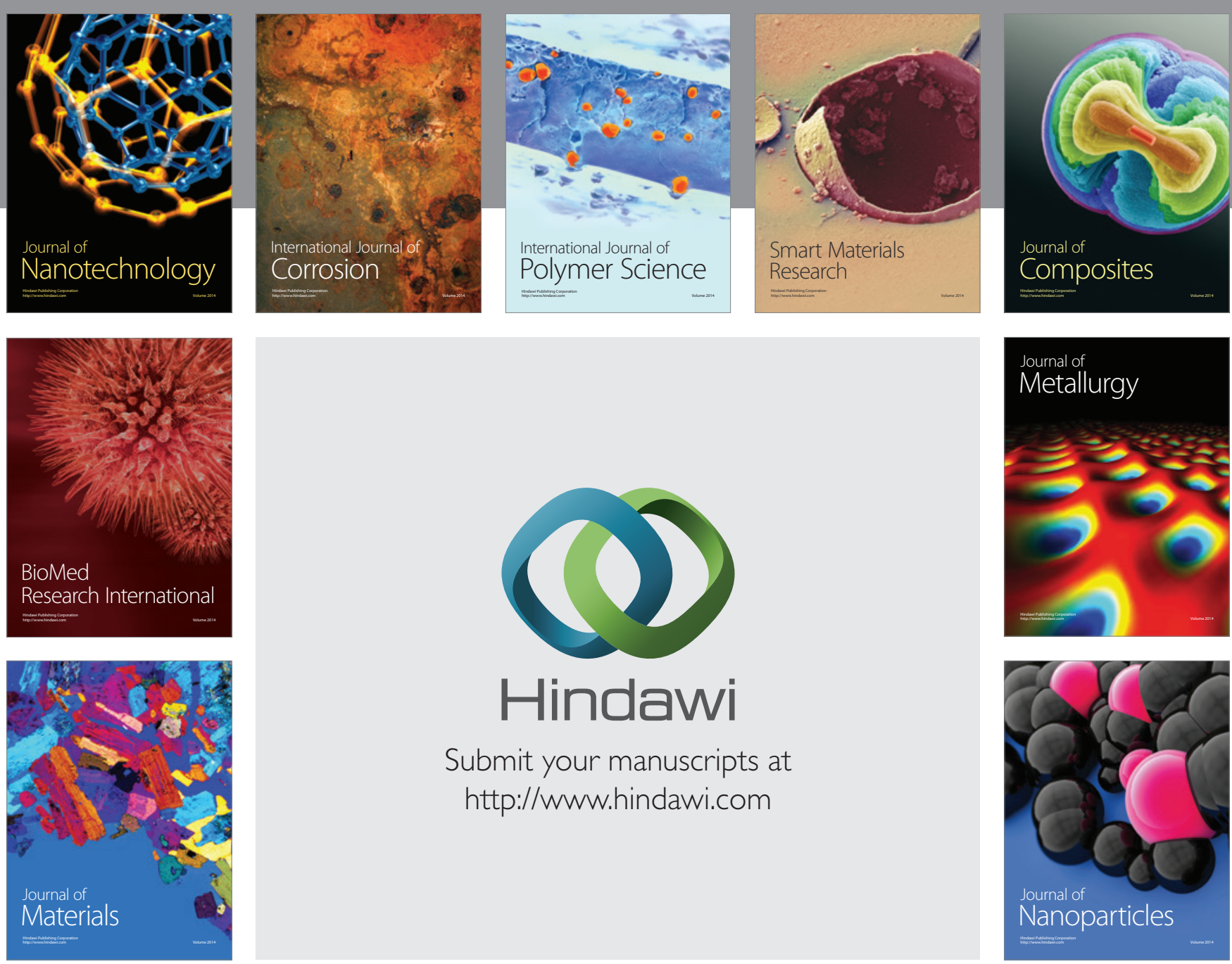

Submit your manuscripts at http://www.hindawi.com
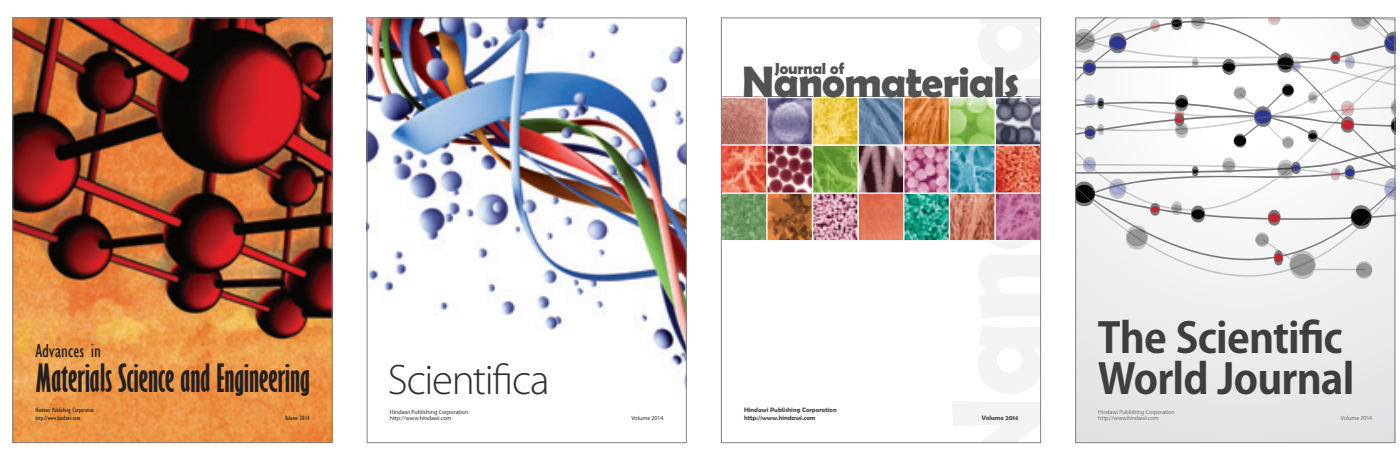

\section{The Scientific World Journal}
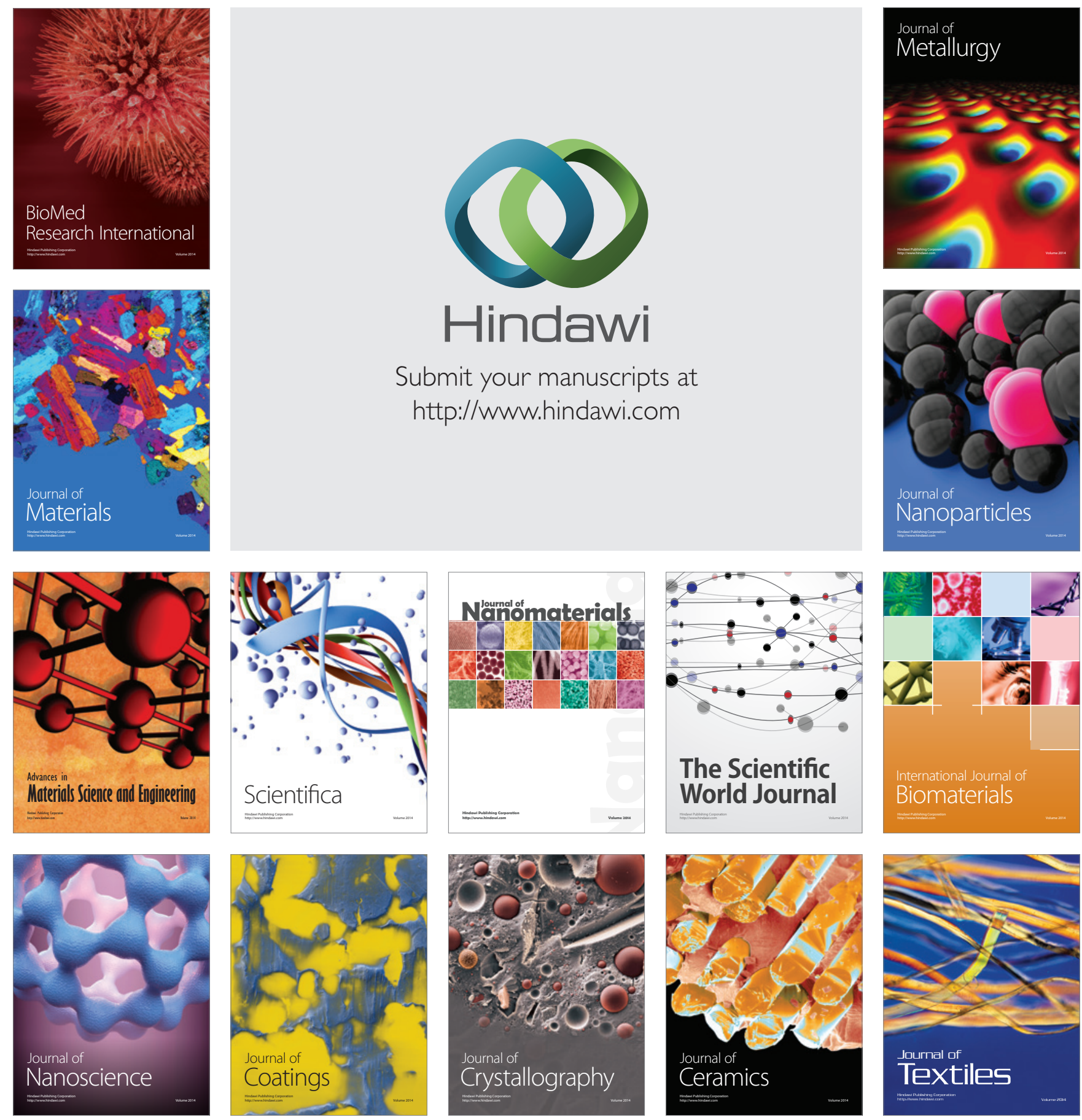